\title{
Relation Between Nanomorphology and Performance of Polymer-Based Solar Cells
}

\author{
Almantas Pivrikas ${ }^{1,2}$ \\ ${ }^{1}$ Physical Chemistry, Linz Institute for Organic Solar Cells, \\ Johannes Kepler University Linz \\ ${ }^{2}$ School of Chemistry and Molecular Biosciences, Centre for Organic Photonics and \\ Electronics, The University of Queensland, Brisbane \\ Austria
}

\section{Introduction}

Global warming and climate change has sparked the interest in alternative energy sources.(Cox et al., 2000) Although solar power reaching the surface of the Earth is able to meet the demands of humanity at the present,(Turner, 1999) an important question remains: how to convert the solar power into electrical power efficiently and at low costs.(Glaser, 1968) Polymer-based organic solar cells offer a possible solution for low cost photovoltaic energy conversion.(Wohrle \& Meissner, 1991) In general, organic electronics has created an immense academic interest due to unlimited and flexible molecular engineering possibilities, allowing new organic materials with tailored physical properties to be synthesized.(Forrest, 2005b)

The most promising aspect of organic solar cells is their potential economic advantage due to large-scale production posibilities using continuous and large scale roll-to-rool printing and coating techniques allowing to deposit the active film, electrodes, sealing layers, antireflecting coatings and other components on flexible substrates all-at-once.(Krebs, 2009) Various aesthetic form factors, usually considered to be important for the solar panel integration into buildings can be achieved with this type of solar cell. Desired device form, color and a wide range of applications including solar power stations, roof-tops, portable devices, textile integrated power supplies and other consumer products can be envisioned.

The relation between fabrication costs of photovoltaic modules and power conversion efficiency defines the market success, therefore both factors have to be considered from academic and industrial perspective.(Brabec, 2004) Due to low dielectric constants and weak van der Waals forces binding the organic molecules into a solid, excitons (electron and hole pair strongly bounded by Coulomb attraction) are the primary photoexcitations in organic solids.(Schwoerer \& Wolf, 2007) In order to achieve high power conversion efficiency of organic solar cells excitons have to be separated into mobile charge carriers for photocurrent generation.(Forrest, 2005a) The bulk-heterojunction concept is employed to overcome the short exciton diffusion distance. The photoactive film of heterojunction is formed from the donor and acceptor materials which are phase-separated on the nanometer length scale, to facilitate the photo-induced charge transfer as well as create a percolating pathways for charge transport to the electrodes.(Brabec et al., 2001; Halls et al., 1995) Therefore, the 
nanomorphology of polymeric solar cells plays a crucial role for the performance of the devices.

Historically, thermal annealing of the film has been used to induce the phase separation between donor and acceptor in bulk-heterojunction blends.(Padinger et al., 2003) However, thermal treatment creates an additional fabrication step in the whole device fabrication process. Later, various methods have been tested and employed to control the nanomorphology of the blends, namely use of solvents with different boiling points (choice of solvent), reduction of drying speed (rate of drying and vapor annealing), changing the solubility of materials, melting of bilayers and the use of processing additives.(Pivrikas et al., 2010b) The later method has received great academic interest as it removes the need for post-production treatment while at the same time allowing fine control of the nanomorphology in various donor-acceptor blends.(Lee et al., 2008)

In this work the factors limiting the power conversion efficiency of excitonic polymer-based bulk-heterojunction solar cells are discussed. Various methods allowing the film nanomorphology to be controlled are reviewed. The use of processing additives to control the phase separation for the formation of an interpenetrating network and how this impacts the power conversion efficiency is described.

\section{Excitonic polymer-based solar cells}

Polymer-based bulk-heterojunction solar cells (BHSC) have already shown certified efficiencies above $8 \%$ demonstrating ability to compete with inorganic solar cell systems (eg. amorphous silicon cells fabricated on flexible substrates). Efficiencies exceeding 10\% for solution processed solar cells are expected to be achieved soon.(Nayak et al., 2011) The power conversion efficiency of BHSCs is determined by the photophysical processes under operational conditions. A fundamental understanding of the relation between light absorption charge separation, charge transport, recombination, and film nanostructure as well as between the various thin film fabrication and processing parameters (such as solvent composition, solution concentration, deposition atmosphere and process temperature) is needed for further improvements. These important parameters can be controlled to some extent by adjusting the required film composition or device structure.(Gunes et al., 2007)

\subsection{Solar cell device structure}

The typical device structure of most organic optoelectronic devices, including organic light-emitting diodes and solar cells, is shown in Fig. 1. The front electrode is based on a transparent conducting oxide, such as indium tin oxide (ITO), that serves as the high-work-function, positive electrode.(Brabec et al., 2001) To further improve the quality of the ITO electrode and aid hole (positive charge carrier) extraction from the active film, poly(3,4-ethylenedioxythiophene)-poly(styrene sulfonate) (PEDOT-PSS) layer (tens of nanometers thick) is coated on top, forming a smooth surface which is essential in thin film devices. The photoactive film, the donor and acceptor bulk-heterojunction blend is deposited on top of the PEDOT-PSS layer. The whole device is finished by thermally evaporating the back contact (negative electrode) under high vacuum. To achieve the built-in electric field needed for most devices to operate, the back electrode must be made from a low-work-function metal that serves as the negative electrode. In the operation of a typical polymer-fullerene bulk-heterojunction solar cell, electrons generated in the active layer are collected by the back electrode (anode), and holes are collected at the opposite electrode (cathode). 


\subsection{Solar cell fabrication techniques}

While academic research is highly concentrated on improving the power conversion efficiency, there are other important aspects needed for commercial success, such as cell stability, degradation, low manufacturing costs with rapid large scale production. This has been summarized by the Venn diagram as the unification of challenges when trying to combine power conversion efficiency, processability and stability into final devices.(Jorgensen et al., 2008)

Solution processing is attractive for fabricating organic optoelectronic devices mainly due to its simplicity and applicability for large scale and low-cost production. Thin films can be formed in various ways: a) printing techniques including screen printing, pad printing, gravure printing, flexographic printing and offset printing; b) coating techniques including pin coating, doctor blading, casting, painting, spray coating, slot-die coating, curtain coating, slide coating and knife-over-edge coating. The only technique that in both categories is inkjet printing.

Spin coating has been the most common technique for polymeric solar cell fabrication with numerous reviews and fundamental studies available.(Norrman et al., 2005) This technique, widely used in the microelectronics industry to deposit photoresist on silicon wafers, allows for the reproducible formation of highly homogeneous films over large areas. A typical spin coating process involves application of a solution (with the organic semiconductors dissolved in a solvent) to a substrate which is then either accelerated to the required angular velocity or is already spinning at it, Fig. 2.(Krebs, 2009) A large portion of the solution is wasted leaving a thin film on the substrate. Film thickness, morphology and surface topography strongly depend on the rotational speed, viscosity, volatility, diffusivity, molecular weight and concentration of the solutes and solvents used.(Cohen \& Gutoff, 1992)

\subsection{Current-Voltage dependence of solar cells}

The most important figure of merit describing the performance of a solar cell is the power conversion efficiency, which is determined from the current voltage characteristics of the solar cells under operational conditions. Typical current-voltage characteristics of solar cells under illumination is shown in Fig. 3.(Deibel \& Dyakonov, 2010)

The accurate measurement of the PCE according to international standards has been described in the literature,(Shrotriya et al., 2006) and is eesential for reproducibility and comparison of results between different laboratories. The Shockley diode equation describes the

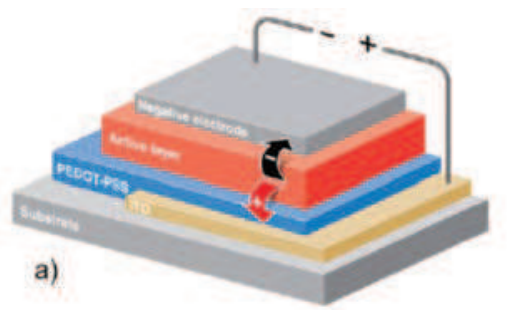

Fig. 1. Schematic sandwich-type structure of organic solar cells showing an organic semiconductor active film between two metal electrodes with different work functions (typically ITO/PEDOT-PSS as positive and Ca/Al as negative contacts). Reprinted with permission from (Shaheen, 2007). Copyright 2007 Society of Photo-Optical Instrumentation Engineers. 


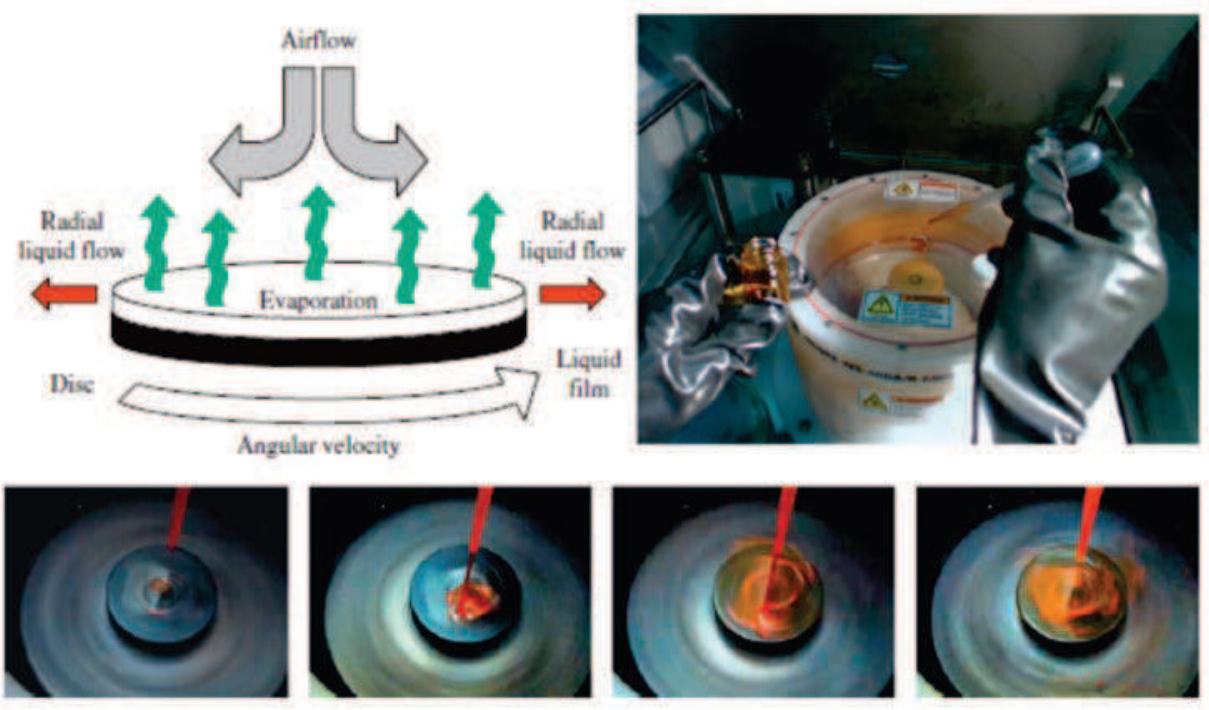

Fig. 2. Spin coating of organic solar cells from solution. Reprinted with permission from (Krebs, 2009). Copyright 2009, with permission from Elsevier.

current-voltage dependence of an ideal diode.(Shockley \& Queisser, 1961) In the dark under forward bias the injection current increases exponentially with applied bias, whereas under reverse bias, current saturates at low applied voltages due to blocking contacts. This leads to a rectifying behaviour as can be clearly seen in the log-lin plot in Fig. 3. A description of the non-ideal device (typical organic solar cells) requires addition of series (Rs) and paralell $(\mathrm{Rp})$ resistances. Rs is connected in series with the ideal diode and it describes the contact resistances such as injection barriers and sheet resistances. Rp arises due to the influence of local shunts between the two electrodes, i.e. additional current paths circumventing the diode. Typically in organic solar cells, a strong photocurrent dependence of applied electric field is observed manifesting as a non-saturated current at $-1 \mathrm{~V}$ reverse bias (Fig. 3 ). The field-dependent photocurrent arises due to:

a) field dependent mobile charge carrier generation, since an exciton has to dissociate into mobile carriers;(Oesterbacka et al., 2010)

b) charge carrier collection due to Hecht's law, if the extracted charge saturates at electric fields wheere the film thickness is larger than the carrier drift distance.(Hecht, 1932)

c) electric field dependent carrier mobility.(Pivrikas, Ullah, Sitter \& Sariciftci, 2011)

In addition to electric field dependent mobility, the charge transport in disordered organic solar cells is also carrier concentration dependent. This effect arises due to the hopping nature of charge transport, where at higher carrier concentrations the carrier hopping probability between localized states increases (loosely speaking due to a higher density of localized states resulting in better electron wavefunction overlap) and therefore the carrier mobility increases.(PIVRIKAS, ULLAH, SINGH, SIMBRUNNER, MATT, SITTER \& SARICIFTCI, 2011) 

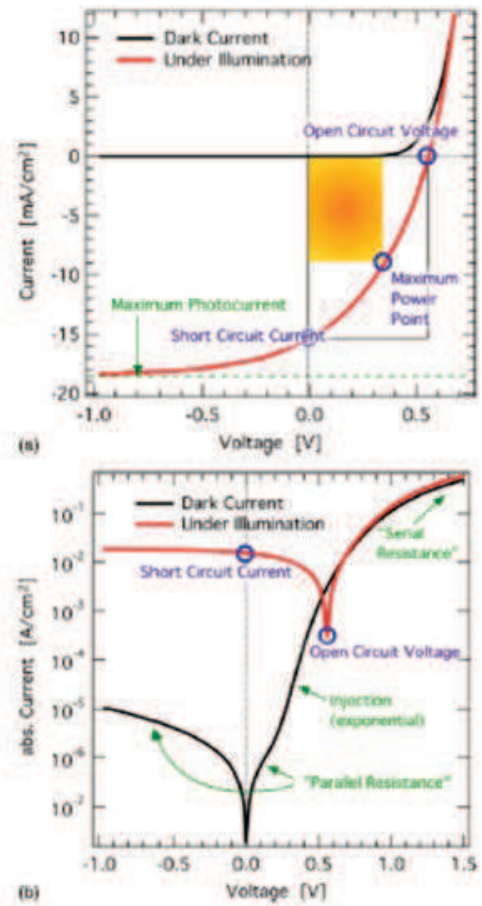

Fig. 3. Typical schematic current-voltage (I-V) dependence of the organic solar cell in the dark and under illumination. Reprinted with permission from (Deibel \& Dyakonov, 2010). Copyright 2010, with permission from Institute of Physics.

\subsection{Power conversion efficiency}

PCE is defined as the ratio of the electrical power produced by a solar cell to the optical power of incident light $\left(P_{\text {light }}\right)$ :(Luque \& Hegedus, 2003)

$$
P C E=\frac{j_{S C} V_{O C} F F}{P_{\text {light }}}
$$

where $j_{S C}$ is the short circuit current density, $V_{O C}$ is the open circuit voltage, $F F=$ $V_{M P} j_{m p} / V_{O C} j_{S C}$ is the fill factor representing the maximum area in the fourth quadrant of the I-V characteristics of solar cells, $V_{M P}$ and jmp are the voltage and current, respectively, at the point of maximum power, and $P_{\text {light }}$ is the power of incoming light under Standard Test Conditions (1000 W/m2, AM 1.5 (Air Mass) solar reference spectrum, temperature during measurements $25 \mathrm{C}$ ).[15] To maximize the PCE values, all these parameters have to be maximized. The open circuit voltage of BHSC is determined by the energy of the quasi-Fermi levels of both semiconductors (donor and acceptor) as well as the Fermi levels of the electrodes.(Scharber et al., 2006) The short circuit current $j_{S C}$ depends on electrical carrier drift (induced by electric field) and diffusion (induced by concentration gradient). Apart from the absorption on the film, charge carrier concentration and mobility are the main factors influencing the photocurrent regardless of the transport mechanism (drift or diffusion).(Nelson, 2003) 


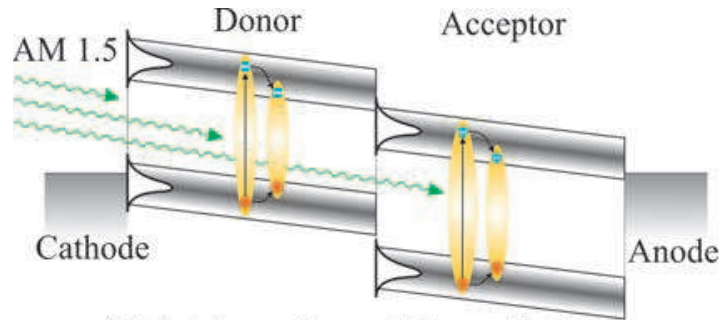

a) light absorption and thermalisation

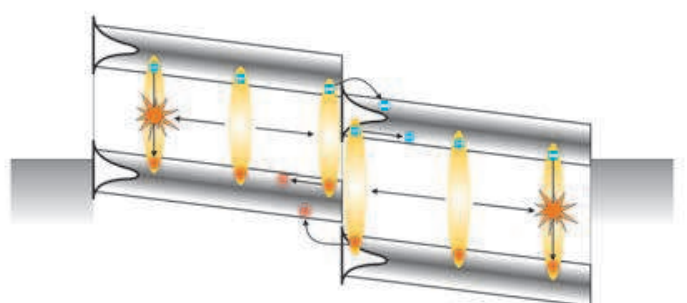

b) exciton diffusion, dissociation and recombination

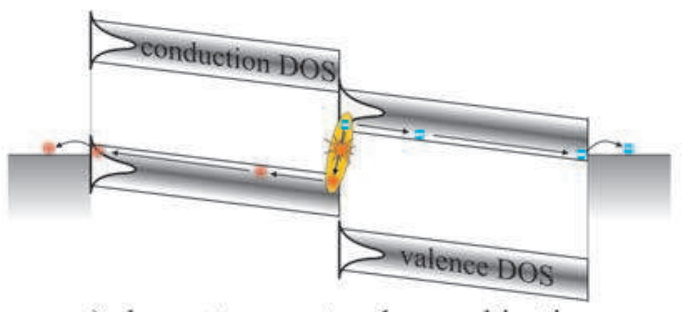

c) charge transport and recombination

Fig. 4. Factors limiting power conversion efficiency of excitonic solar cells. Reprinted with permission from (Pivrikas, 2010). Copyright 2010 IEEE.

The PCE of organic solar cells is influenced by many different photophysical processes and parameters. Simplified energy-level diagrams of organic solar cells utilizing donor and acceptor materials is shown in Fig. 2.(Pivrikas et al., 2010a)

\subsection{Power conversion efficiency limiting mechanisms in excitonic solar cells}

The first factor limiting the PCE is the absorption of light in the film. Ideally, as much as possible of the incident solar irradiance should be absorbed.(Pivrikas et al., 2010a) The Beer-Lambert law determines the light absorption profile in homogeneously distributed and scatter-free medium. Optical interference effects can also influence the light absorption profile in thin multilayer films.(Dennler et al., 2009) As can be seen in Fig. 4 some part of absorbed light energy is lost due to a thermalization process - charge relaxtion within the Density of States (DOS) to the lower energy levels to form an occupational-DOS within localized DOS.(Bassler, 1993; Juska et al., 2003; Osterbacka et al., 2003)

The second efficiency limiting process is exciton dissociation into mobile charge carriers. Due to low dielectric constants and consequently weak Coulombic field screening in the organic 
materials (relative static permittivity is around 3) the primary photoexcitation is an exciton, which does not create the photocurrent.(Luque \& Hegedus, 2003) The exciton diffusion length describes how far an exciton can diffuse within its lifetime. The concept of heterojunction between two organic semiconductors (donor and acceptor) is used to split an exciton into mobile charge carriers. Efficient exciton dissociation (charge transfer) takes place at the interface between donor and acceptor if a suitable offset in energy level exists, as shown in Fig. 4 b).(Pivrikas et al., 2010a) The excited state Charge Transfer (CT) complex (sometimes called exciplex) might be formed after the dissociation of an exciton meaning that positive and negative charge carriers might remain bounded by the Coulomb attraction at the donor acceptor interface, which would not contribute to photocurrent.

The charge carrier transport (collection) to the electrodes is the third important limiting processes. As shown in Fig. $4 \mathrm{c}$ ), mobile electrons and holes must be transported to the opposite electrodes. The driving force can be either diffusion, related to the carrier concentration gradients, and/or drift due to a built-in electric field. An important aspects of charge transport are the charge extraction at the semiconductor-metal interface. The energy level alignment between the metal and semiconductor, free charge carrier concentration in the film (doping level) as well as the trapping level concetration, carrier capture and release times from capture centers determine the interfacial properties of the device. Non-blocking contact without energetical barrier for charge carrier extraction is required to be present at the interface.(Baranovski, 2006) The disordered nature of solution processed films of organic semiconductors results in low charge carrier mobilities (tzpically $10^{-3}-10^{-7}$ $\mathrm{cm}^{2} \mathrm{~V}^{-1} \mathrm{~s}^{-1}$ in $\pi$-conjugated polymers). The mobility of the slower charge carrier limits the photocurrent, and therefore the efficiency of the solar cell due to accumulation of charge carriers. Since the photocurrent under operation conditions typically approach space charge limited current, second order recombination processes become dominant due to high charge carrier concentration, and the carrier lifetime becomes shorter than the transit time.(Pivrikas et al., 2010a)

\subsection{Bulk-heterojunction solar cells}

The light absorption coefficient, $\alpha$, in a disordered organic film is usually high, on the order of $10^{5} \mathrm{~cm}^{-1}$. This allows thin films, on the order of hundreds of nanometers, to be used in solar cells. However, the exciton diffusion length in most organic materials is of the order of $10 \mathrm{~nm}$. If the exciton is to diffuse to the interface between the two materials (donor-acceptor) in order to separate into mobile charge carriers, these two materials must be blended on this length scale. Furthermore, the donor-acceptor phases must for bi-continuous network with percolating pathways for electron and hole transport to the elctrodes. This is the operating principle of the BHSC shown in Fig. 5.(Sariciftci, 2006) The film nano-morphology is crucially important for the efficiency of solar cells.(Ma et al., 2005) The nanoscale phase-separation phase separation between donor and acceptor in BHSC plays an important role relating the device properties and performance to the solar cell fabrication methods. Typical donor is poly(3-hexylthiophene-2,5-diyl) (P3HT) and acceptor is [6,6]-phenyl-C61-butyric acid methyl ester (PCBM)

\section{Methods to control the morphology of BHSC}

The formation and the size of nanoscale domains of donor and acceptor phases are strongly dependent on the film fabrication techniques and conditions. Beyond the selection of suitable materials there are several parameters that must be carefully controlled when fabricating 


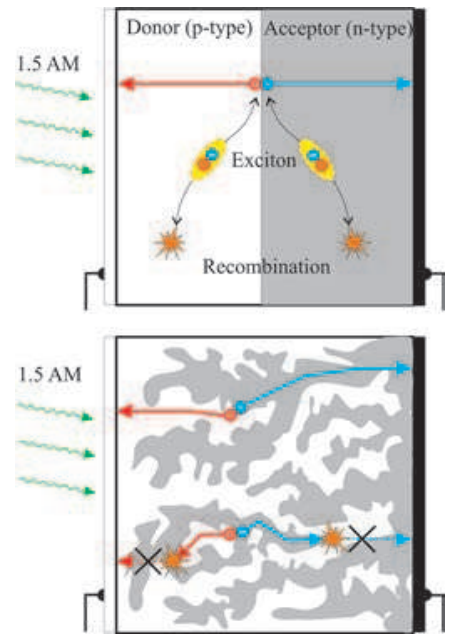

Fig. 5. Bilayer and bulk-heterojunction solar cells. Reprinted with permission from (Pivrikas et al., 2010a). Copyright 2009, with permission from Elsevier.

BHSC, such as the solution concentration, deposition temperature, donor-acceptor blend ratio, spin speeds using solvents with different boiling points, solvent evaporation kinetics, vapour pressure, solubility, and polarity.(Pivrikas et al., 2010b)

Various methods allowing the control of the film nano-morphology have been introduced in the past.(Chen, Hong, Li \& Yang, 2009; Peet et al., 2009) Initially it was observed that the PCE of BHSC significantly increases upon a postproduction treatment, e.g. thermal annealing of solar cells with applied external voltage.(Hoppea \& Sariciftci, 2004; Padinger et al., 2003) Other methods used in the past to control the morphology of BHSC involve the use of appropriate solvents with specific boiling point that allow either the increase or decrease of the solvent evaporation rate.(Kim, Choulis, Nelson, Bradley, Cook \& Durrant, 2005; Shaheen et al., 2001; Yu et al., 1995) Other methods, such as reducing the drying speed of spin-coated films,(Li et al., 2005; Mihailetchi et al., 2006; Vanlaeke et al., 2006) solubility matching(Troshin et al., 2009) and the melting of bilayers have also been used.(Kim, Liu \& Carroll, 2006) It was observed that chemical additives can substitute the post production treatment of BHSC.(Lee et al., 2008) Processing additives are an attractive concept due to the simplicity and suitability for large scale production.

\subsection{Thermal annealing of devices}

Thermal annealing, by controlling the temperature and annealing time, is typically applied to either the final device or $\mathrm{BHJ}$ films in order to improve the nanoscale phase separation between donor and acceptor.(Ma et al., 2005; Sun et al., 2007; Xin et al., 2008; Zhang, Choi, Haliburton, Cleveland, Li, Sun, Ledbetter \& Bonner, 2006) Significant improvement in photovoltaic performance after annealing is typically observed in P3HT/PCBM blends.(Padinger et al., 2003) Thermal annealing has the advantage in that it can be applied independently of the film deposition technique. Thermal annealing has also been shown to enhance the crystallinity of the polymer, such as for P3HT, increasing the PCE and the photocurrent due to increased carrier mobility.(Erb et al., 2005) Furthermore, the interconnections between the polymer/fullerene phazes in the interpenetrating network are 
enhanced as a result of phase separation between the donor and acceptor on meso (>100 $\mathrm{nm}$ ) and nanoscales $(<20 \mathrm{~nm})$.(Kim, Cook, Tuladhar, Choulis, Nelson, Durrant, Bradley, Giles, McCulloch, Ha et al., 2006; Ma et al., 2005)

The effect of thermal annealing on film morhology was clearly demonstrated by bright-field (BF) transmission electron microscopy (TEM) images, recorded in slight defocussing conditions in a P3HT/PCBM blends, as shown in Fig. 6.(Yang et al., 2005)
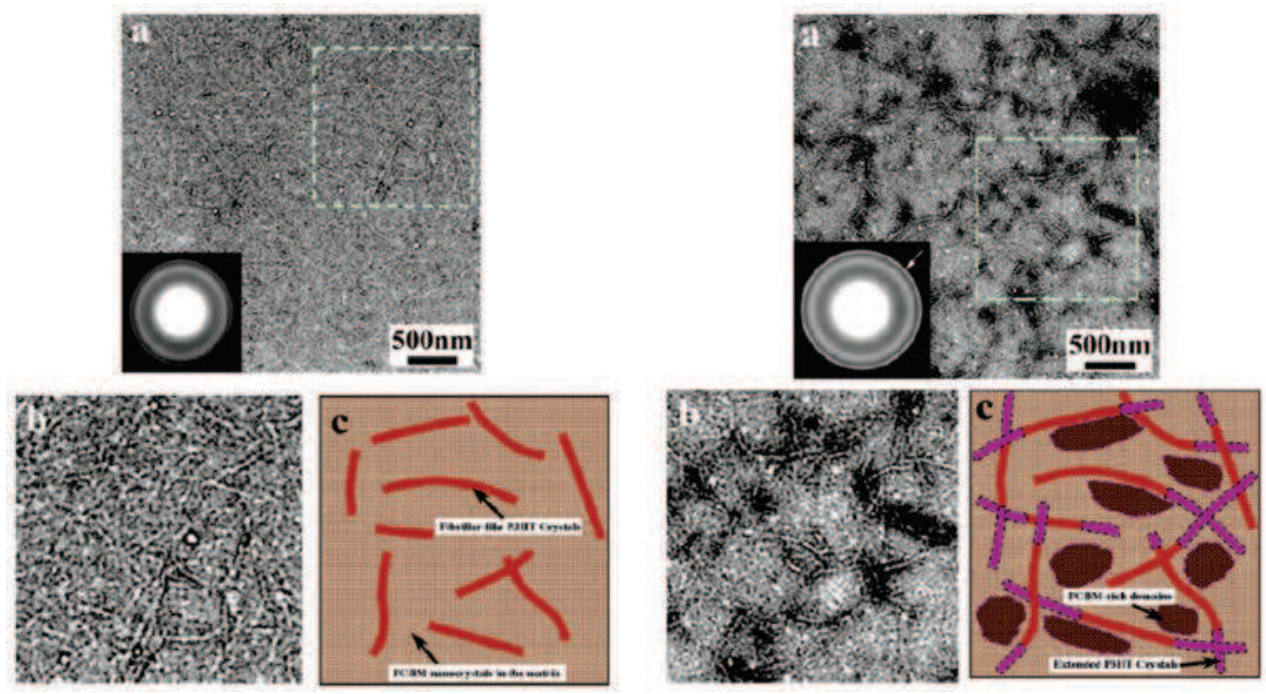

Fig. 6. Transmission Electron Microscopy (TEM) images show the overview (a) and zoomed in (b), and the corresponding schematic representation (c) of the photoactive layer solar cells. Left (a)-(c) images: pristine unannealed P3HT and PCBM blend. Right (a)-(c) images: thermal annealed P3HT and PCBM blend. Insets in (a) figures is the corresponding SAED pattern. The dash line bordered regions represent the extension of existing P3HT crystals in the pristine film or newly developed PCBM-rich domains during the annealing step. The arrow is to indicate the increased intensity of (020) Debye-Scherrer ring from P3HT crystals compared to the SAED pattern shown in the inset of Figure 2a. Reprinted with permission from (Yang et al., 2005). Copyright 2005 American Chemical Society.

As can be seen, fibrillar-like P3HT domains (brighter in contrast compared to background) overlap with each other over the whole film. The inset of Fig. 6 shows the selected area electron diffraction (SAED) pattern of the film. The outer ring corresponds to a distance of 0.39 $\mathrm{nm}$, which is typical pi-pi stacking distance of P3HT chains.(Ihn et al., 1993) The crystallinity of $\mathrm{P} 3 \mathrm{HT}$ crystals is not very pronounced as seen from the low intensity of the reflection ring. The inner ring in the SAED pattern, corresponding to a d-spacing of $0.46 \mathrm{~nm}$, is seen to be even more diffuse and has been attributed by the nanometer sized PCBM nanocrystals that are homogeneously dispersed throughout the film. Fig. 6 a) shows the BF TEM images of the composite film after annealing $(120 \mathrm{C}$ for $60 \mathrm{~min})$. The most pronounced feature in the BF TEM image of the annealed sample is the increased contrast and the appearance of bright fibrillar P3HT crystals throughout the entire film. The width of these crystals remains almost constant compared to the pristine composite film, but on average their length was found to increase over $50 \%$. The increased crystallinity of P3HT after thermal treatment 
is visible from the increased intensity of the reflection ring in the SAED pattern (inset of Fig. 6 a)). Larger and darker PCBM rich areas can be observed suggesting an increased phase demixing between P3HT and PCBM. It was concluded that the crystallinity of P3HT is improved upon annealing and the demixing between the two components is increased, but large-scale phase separation does not occur. The resulting interpenetrating networks composed of P3HT crystals with a high aspect ratio and aggregated nanocrystalline PCBM domains provide continuous pathways in the entire photoactive layer for efficient hole and electron transport.

In order to further understand the extent of thermal annealing, 2-D X-ray scattering in a grazing incidence geometry (GIWAXS) was used to study the development of the crystalline structure of $\mathrm{P} 3 \mathrm{HT}$ and PCBM during the interdiffusion process at various temperatures. 2D GIWAXS patterns of as-prepared P3HT/PCBM bilayers and annealed samples are shown in Fig. 7.(Treat et al., 2011) The diffraction patterns for P3HT shows that the $a$-axis of the P3HT crystals is predominantly oriented perpendicular to the substrate and the $b$-axis ( pi-stacking)
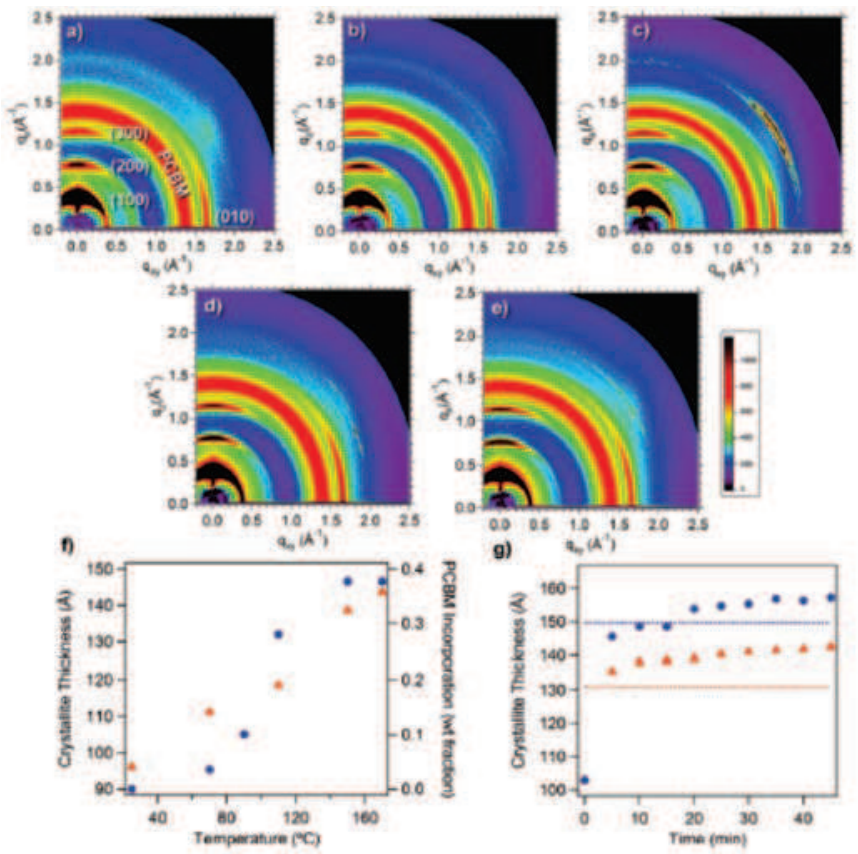

Fig. 7. Two-dimensional GIWAXS of a P3HT/PCBM bilayer on Si a) as-cast and annealed at b) $70 \mathrm{C}, \mathrm{c}) 110 \mathrm{C}$, d) $150 \mathrm{C}$, and e) $170 \mathrm{C}$ for $5 \mathrm{~min}$. f) The Scherrer equation was used to extract the $\mathrm{P} 3 \mathrm{HT}$ crystallite thickness along the a- axis from the full-width-at-half-maximum of the (100) reflection. PCBM incorporation from the DSIMS measurements was plotted for comparison at various annealing temperatures. g) Growth in the crystal thickness with time using in-situ heating 2D GIWAXS of a P3HT / PCBM bilayer on Si at $110 \mathrm{C}$ (orange) and $170 \mathrm{C}$ (blue). The Scherrer equation was used to determine crystal thickness from the (100) reflection corresponding to $\mathrm{P} 3 \mathrm{HT}$. The dotted line corresponds to a neat $\mathrm{P} 3 \mathrm{HT} / \mathrm{Si}$ sample heated for $5 \mathrm{~min}$ at $110 \mathrm{C}$ (orange) and $170 \mathrm{C}$ (blue). Copyright 2011 Wiley. Used with permission from (Treat et al., 2011). 
is oriented parallel - which is the typically observed P3HT orientation. Upon annealing the as-prepared films at various temperatures, the d-spacing along the $a$-axis of the P3HT crystal was found to remain constant, indicating that during the interdiffusion process, the PCBM does not interpenetrate between the side chains of the P3HT crystal structure.(Mayer et al., 2009) The peak width of the diffraction ring, corresponding to the aggregates of PCBM does not change during the interdiffusion process, showing that PCBM remains in an amorphous state with aggregates large enough to scatter incident X-rays. Only a small change in the distribution of P3HT crystal orientations was found to be present at various levels of interdiffusion, while the intensity of the (200) peak of P3HT increased by nearly a factor of two on annealing at $170 \mathrm{C}$. It was shown that the interdiffusion process has little effect on the crystalline regions of the P3HT film, where the diffusion of PCBM into P3HT occurs within the disordered regions of P3HT.

To determine how interdiffusion within this system affects the growth of the P3HT crystallites, the P3HT crystallite size along the $a$-axis for the bilayer films was compared to pure P3HT films heated under similar conditions (Fig. 7 (f)-(g)). The P3HT crystallite size was estimated using the Scherrer equation and plotted against the fraction of PCBM within the P3HT layer (Fig. 7 (f) ). The crystallite size was found to increase with increasing annealing temperature regardless of the level of interdiffusion. The P3HT crystallite size in the bilayer system was found to increase most rapidly during the first $5 \mathrm{~min}$ of annealing, where the crystallite thickness was approching that for a neat P3HT film heated under similar conditions (Fig. $7(\mathrm{~g}))$.

\subsection{Solvent effects}

Postproduction treatment requires a rather well controlled environment, it adds an additional fabrication costs to the solar cell manufacturing process, which might not be attractive for large-scale industrial production. Furthermore, some material systems, like the low band gap organic semiconductor poly[2,6-(4,4-bis-(2-ethylhexyl)-4H-cyclopenta[2,1-b;3,4-b0]dithiophene)-alt-4,7-(2,1,3-benzothiadiazole)] (PCPDTBT) blended with [6,6]-phenyl C71-butyric acid methyl ester (C71-PCBM), do not shown any improvement upon thermal annealing.

Phase separation and molecular self-organization can be influenced by solvent evaporation since the solvent establishes the film evolution environment. Slow drying or solvent annealing techniques have also been used to control the morphology of the blends by changing the rate of solvent removal.(Li et al., 2005; Li, Yao, Yang, Shrotriya, Yang \& Yang, 2007; Sivula et al., 2006) The use of different solvents and their effect on the film nano-structure of BHSC has been studied in detail in the past.(Li, Shrotriya, Yao, Huang \& Yang, 2007) High boiling point solvents were used with the device placed in an enclosed container, in which the atmosphere rapidly saturates with the solvent.

Grazing-incidence x-ray diffraction (GIXRD) studies provided evidence that the solvent evaporation rate directly influences the polymer chain arrangement in the film.(Chu et al., 2008) It was shown that the use of higher boiling point solvent strongly improves the PCE of MDMO-PPV and PCBM blends.(Shaheen et al., 2001) Higher PCE values due to improved film morphology and crystallinity have been reached by substituting chloroform with chlorobenzene for P3HT / PCBM BHSC.(Ma et al., 2005) The difference between chlorobenzene and 1,2-dichloro benzene for use as a solvent was shown in the novel low bandgap polymer PFCo-DTB and C71-PCBM blend systems, where chlorobenzene resulted in films with higher 
roughness.(Yao et al., 2006) Non-aromatic solvents have shown to be able to affect the photovoltaic performance of MEH-PPV and PCBM blends.(Yang et al., 2003)

An interesting method to study the morphology of BHSC optically by recording exciton lifetime images within the photoactive layer of P3HT and PCBM has been demonstrated by Huan et al.(Huang et al., 2010) Using a confocal optical microscopy combined with a fluorescence module they were able to image the spacial distrubution of exciton lifetime for both slow and fast dried films, as shown in Fig. 8.

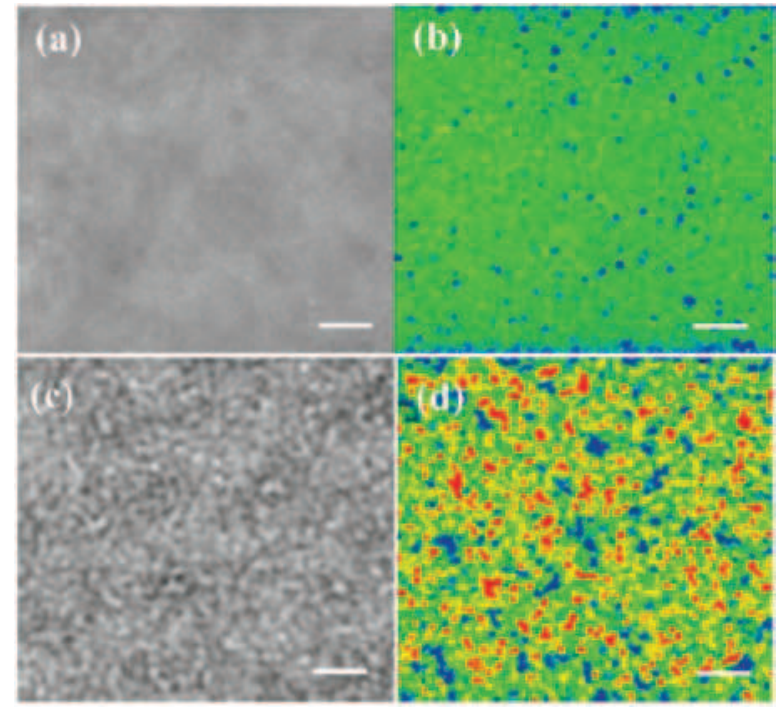

Fig. 8. (a, c) Transmitted images and (b, d) exciton lifetime images of the BHJ film prepared from rapidly and slowly grown methods, respectively, measured after excitation at $470 \mathrm{~nm}$ using a picosecond laser microscope $(512 \times 512$ pixels $)$. Scale bars: $2 \mu \mathrm{m}$. Reprinted with permission from (Huang et al., 2010). Copyright 2010 American Chemical Society.

The transmitted image of the rapidly grown film (Fig. 8 (a)) shows a uniform and featureless characteristics throughout the structure, indicating that P3HT and PCBM were mixed well within the films. This monotonous transmitted image corresponds to a uniform exciton lifetime distribution. Fig. 8 (c)-(d) shows transmitted and exciton lifetime images for the slowly dried films. The bright spots are emissions from many polymer chains that have stacked or aggregated into a bulk cluster leading to a reduced PL quenching. The red regions (P3HT-rich domains Fig. 8 (d)) correspond to the bright spot of the transmitted image (Fig. 8 (c)). In agreement with previous studies, the images showed that the active layers during slow solvent evaporation provide a 3D pathways for charge transport reflecting better cell performance.

\subsection{Processing additives}

This method is based on the usage of a third non-reacting chemical compound, a processing additive, to the donor and acceptor solution. Improvement of the performance of polymer/fullerene photovoltaic cells doped with triplephenylamine has been reported.(Peet et al., 2009) The ionic solid electrolyte (LiCF3SO3) used as a dopant also resulted in enhanced PCE of MEH-PPV/PCBM blends due to an optimized polymer morphology, improved 
electrical conductivity and in situ photodoping.(Chen et al., 2004) A copolymer including thieno-thiophene units (DHPT3) has been used as a nucleating agent for crystallization in the active layer of P3HT and PCBM BHSC.(Bechara et al., 2008) It was demonstrated that the addition of DHPT3 in P3HT/PCBM thin films induces a structural ordering of the polythiophene phase, leading to improved charge carrier transport properties and stronger active layer absorption. High-performance P3HT/PCBM blends were fabricated using quick drying process and 1-dodecanethiol as an additive.(Ouyang \& Xia, 2009) Ternary blends of P3HT, PCBM and poly(9,9-dioctylfluorene-co-benzothiadiazode) (F8BT) showed enhanced optical absorption and partly improved charge collection.(Kim, Cook, Choulis, Nelson, Durrant \& Bradley, 2005) A few volume percent of 1,8-diiodooctane in o-xylene was used to dissolve poly(9,9-di-n-octylfluorene) PFO allowing the control of film morphology.(Peet et al., 2008) Block-copolymers and diblock copolymers with functionalized blocks have also shown to be able to influence the film morphology.(Sivula et al., 2006; Sun et al., 2007; Zhang, Choi, Haliburton, Cleveland, Li, Sun, Ledbetter \& Bonner, 2006)

\subsubsection{1 "Bad" solvent effect}

The incorporation of other solvents into the host solvent is capable of controlling the film morphology of BHSC.(Chen et al., 2008; Wienk et al., 2008; Xin et al., 2008; Zhang, Jespersen, Björström, Svensson, Andersson, Sundstr"om, Magnusson, Moons, Yartsev \& Ingan"as, 2006) In some cases, changes in the solvent composition lead to interchain order that cannot be obtained by any other method.(Campbell et al., 2008; Moulee et al., 2008; Peet et al., 2007) The use of nitrobenzene as an additive has been shown to improve the phase-separation between the donor and acceptor (P3HT/PCBM blend), where P3HT was shown to be present in both amorphous and crystalline phase.(Moule \& Meerholz, 2008; van Duren et al., 2004)

a)

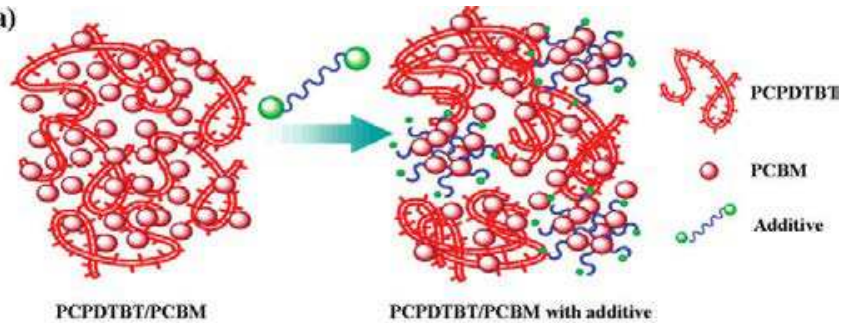

b)

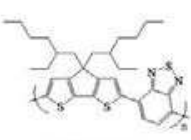

PCPDTBT

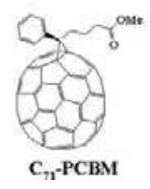

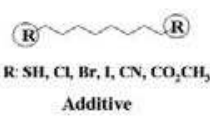

Additive

Fig. 9. Schematic depiction of the role of the processing additive in the self-assembly of bulk heterojunction blend materials (a) and structures of PCPDTBT, C71-PCBM, and additives (b). Reprinted with permission from (Lee et al., 2008). Copyright 2008 American Chemical Society.

The concept of mixing a host solvent with a "bad" solvent has been explored resulting in solvent-selection rules for desired film morphology.(Alargova et al., 2001) Solvents, distinctly dissolving one component of the blend, induce the aggregation of nanofibers and nanoparticles in the solvent prior to film deposition.(Yao et al., 2008) It was shown 
that (independent of the concentration of the additive) fullerene molecules crystallized into distributed aggregates in the presence of a "bad" solvent in the host solvent. Well aligned P3HT aggregates resulting in high degree of crystallinity due to the interchain $\pi-\pi$ stacking were observed upon addition of hexane.(Li et al., 2008; Rughooputh et al., 1987) The addition of 1-chloronaphthalene (a high boiling point solvent) into dichlorobenzene has also resulted in similar self-organization of polymer chains.(Chen et al., 2008) It was shown that in the blends of poly(2,7-(9,9-dioctyl-fluorene)-alt-5,5-(40,70-di-2-thienyl-20,10,3-benzothiadiazole)) and PCBM dissolved in chloroform with a small addition of chlorobenzene, a uniform domain distribution was attained, whereas the addition of xylene or toluene into the chloroform host solvent resulted in larger domains, stronger carrier recombination and a smaller photocurrent. Alkane-thiol based compounds were extensively used as processing additives in the past.(Lee et al., 2008) The photoconductivity response was shown to increase strongly in polymer/fullerene composites by adding a small amount of alkane-thiol based compound to the solution prior to the film deposition.(Coates et al., 2008; Peet et al., 2006) By incorporating a few volume percent of alkanethiols into the PCPDTBT/C71-PCBM BHSC (Fig. 9) it was shown that the PCE improves almost by a factor of two.(Alargova et al., 2001; Peet et al., 2007)

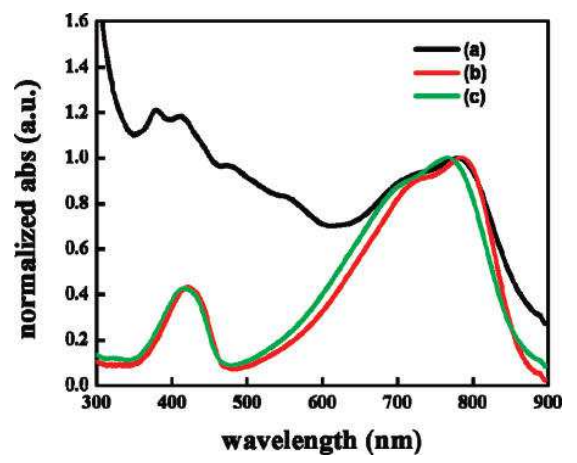

Fig. 10. UV-visible absorption spectra of PCPDTBT/C71-PCBM films processed with 1,8-octanedithiol: before removal of C71-PCBM with alkanedithiol (black); after removal of C71-PCBM with alkanedithiol (red) compared to the absorption spectrum of pristine PCPDTBT film (green). Reprinted with permission from (Lee et al., 2008). Copyright 2008 American Chemical Society.

The alkanedithiol effect was explained by the ability of alkanedithiols to selectively dissolve the fullerene component, where the polymer is less soluble, Fig. 9 The effect has been proven by removing the fullerene domains by dipping the $\mathrm{BHJ}$ film into an alkanedithiol solution and measuring light absorption before and after dipping.(Lee et al., 2008) The normalized absorption spectra (shown in Fig. 10) demonstrate that after dipping the film the absorption matches that of the pristine polymer.

As a consequence, "bad" solvent addition provides a means to select solvent-additives in order to control the phase-separation in BHSC. It was shown that during film processing the fullerene stays longer in its dissolved form, due to the rather high boiling point of alkanedithiol (> 160 C), allowing for self-aligning and phase-separation between the polymer and fullerene as suggested in Fig. $7 \mathrm{~b}$ ). Two effects control the morphology of the blends:

a) selective solubility of one of the components;

b) a high boiling of the additive compared to the host solvent. 
The concentration of the processing additive allows the amount of phase-separation between the donor and the acceptor to be controlled.

\subsubsection{Different processing additives}

1,8-di(R)octanes with various functional groups $(\mathrm{R})$ allow control of the film morphology.(Peet et al., 2007) The best results were obtained with 1,8-diiodooctane. Progressively longer alkyl chains, namely 1,4-butanedithiol, 1,6-hexanedithiol, 1,8-octanedithiol or 1,9-nonanedithiol were used to manipulate the morphology of solution processed films. It was concluded that approximately six methylene units are required for the alkanedithiol to have an appreciable effect on the morphology.

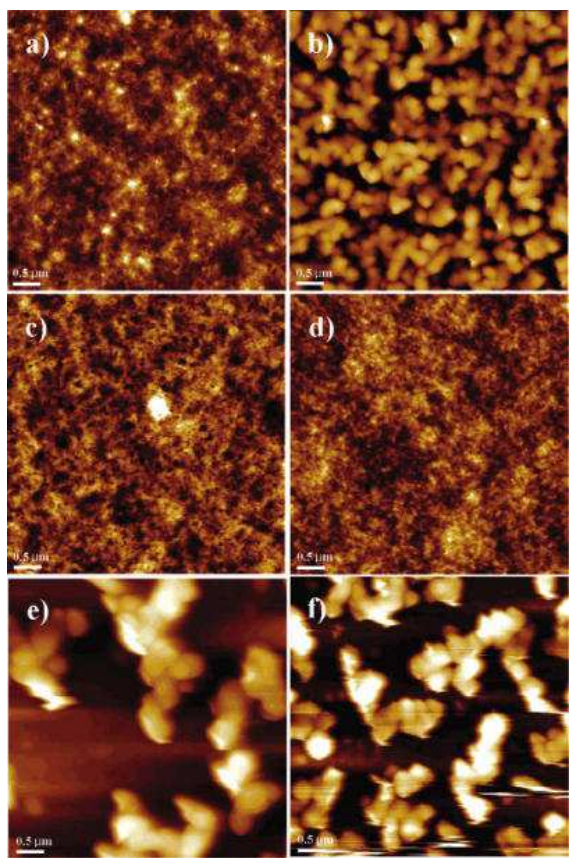

Fig. 11. AFM topography of films cast from PCPCTBT/C71-PCBM with additives: (a) 1,8-octanedithiol, (b) 1,8-cicholorooctane, (c) 1,8-dibromooctane, (d) 1,8-diiodooctane, (e) 1,8-dicyanooctane, and (f) 1,8-octanediacetate. Reprinted with permission from (Chen, Yang, Yang, Sista, Zadoyan, Li \& Yang, 2009). Copyright 2009 American Chemical Society.

Fig. 11 shows a Atomic Force Microscopy (AFM) surface topography of films cast from PCPCTBT/C71-PCBM with the various processing additives.(Lee et al., 2008) The 1,8-octanedithiol (a), 1,8-dibromooctane (c), and 1,8-diiodooctane (d) resulted in phase-segregated morphologies with finer domain sizes than those obtained with 1,8-dichlorooctane (b), 1,8-dicyanooctane (e), and 1,8-octanediacetate (f). The morphology of films processed with 1,8-diiodooctane showed more elongated domains than those processed with 1,8-octanedithiol and 1,8-dibromooctane. The 1,8-di(R)octanes with $S H, B r$, and $I$, gave finer domain sizes and exhibited more efficient device performances than those with $\mathrm{R}=\mathrm{Cl}$, $\mathrm{CN}$, and $\mathrm{CO}_{2} \mathrm{CH}_{3}$. The AFM images of the $\mathrm{BHJ}$ films processed using 1,8-di(R)octanes with 
$R=\mathrm{Cl}, \mathrm{CN}$, and $\mathrm{CO}_{2} \mathrm{CH}_{3}$ showed large scale phase separation with round-shape domains and no indication of a bicontinuous network.

\subsubsection{Concentration of processing additives}

Once the most effective thiol functional group has been indentified, it is interesting to find how the concentration of the processing additive in solution affects the film morphology. The effect of additive concentration in the solution was clearly observed in surface topography images in AFM.(Chen, Yang, Yang, Sista, Zadoyan, Li \& Yang, 2009)

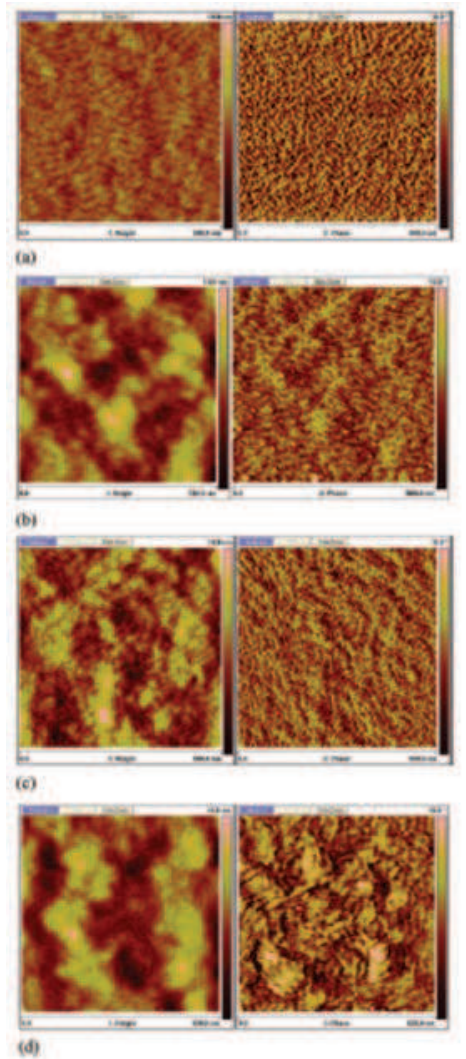

Fig. 12. Tapping mode AFM images of films with different amounts of 1,8-octanedithiol in $500 \mathrm{~nm} \times 500 \mathrm{~nm}$. Left: topography. Right: phase images. (a) $0 \mu \mathrm{L}$, (b) $7.5 \mu \mathrm{L}$, (c) $20 \mu \mathrm{L}$, and (d) $40 \mu \mathrm{L}$ of 1,8-octanedithiol. The scale bars are $10.0 \mathrm{~nm}$ in the height images and $10.0^{\circ}$ in the phase images. Reprinted with permission from from (Chen, Yang, Yang, Sista, Zadoyan, Li \& Yang, 2009). Copyright 2009 American Chemical Society.

AFM images (a), (b), (c), and (d) of Fig. 12 show the height (left) and phase (right) images of polymer films with $0,7.5,20$, and $40 \mu \mathrm{L}$ of 1,8 -octanedithiol, respectively, showing an increasing trend in roughness with increasing amount of 1,8-octanedithiol. The domain sizes were found to be consistent with the higher crystallization observed with increasing amount of 1,8-octanedithiol. Finely dispersed structures were observed when there was no 
1,8-octanedithiol added. The AFM results were consistent with PL spectra showing higher PL intensity with increased 1,8-octanedithiol concentration.

AFM provides information about the film surface only, the bulk of the film has been studied using synchrotron-based grazing incidence X-ray diffraction (GIXD) in P3HT:PCBM blends.(Chen, Yang, Yang, Sista, Zadoyan, Li \& Yang, 2009) Fig. 13 (a) represents 2-D GIXD
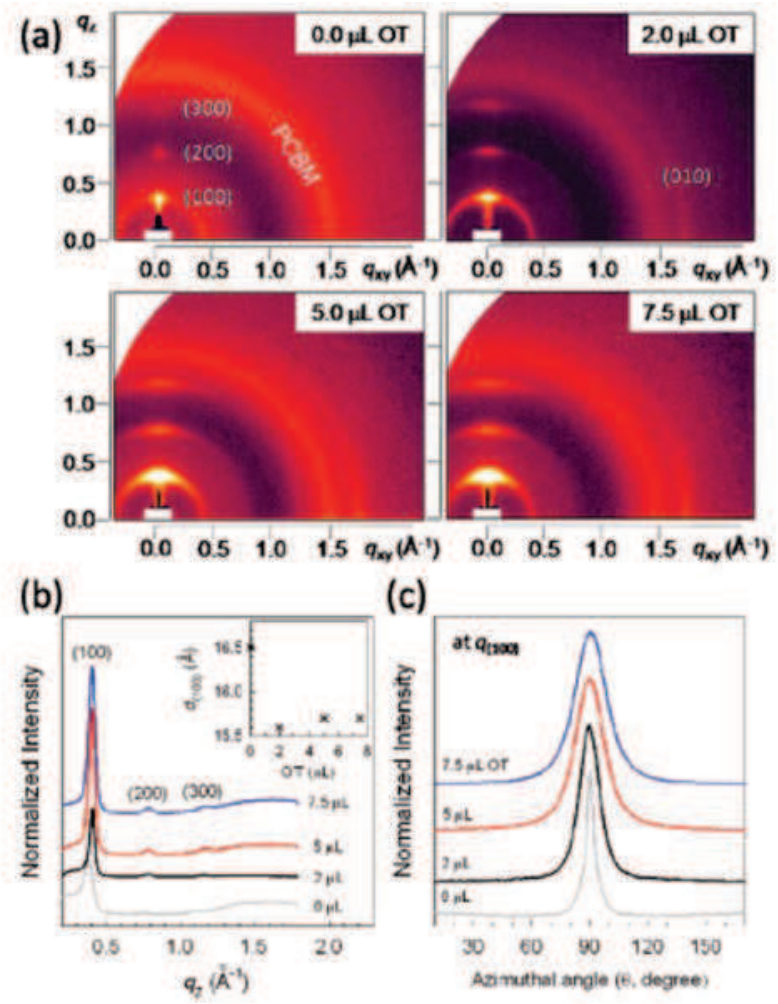

Fig. 13. (a) 2D GIXD patterns of films with different amounts of 1,8-octanedithiol. (b) 1D out-of-plane X-ray and (c) azimuthal scan $\left(\right.$ at $\mathrm{q}^{(100)}$ ) profiles extracted from (a). Inset of b: calculated interlayer spacing in the (100) direction with various amounts of 1,8-octanedithiol. Reprinted with permission from (Chen, Yang, Yang, Sista, Zadoyan, Li \& Yang, 2009). Copyright 2009 American Chemical Society.

patterns of the as-spun P3HT:PCBM films with different concentrations of 1,8-octanedithiol. It was found that the hexyl side chains and backbone of $\mathrm{P} 3 \mathrm{HT}$ are oriented perpendicular and parallel to the surface, respectively regardless of 1,8-octanedithiol concentration. However, the crystallinity of P3HT in the films significantly increases in the presence of 1,8-octanedithiol and tends to keep steady above $5 \mu \mathrm{L}$ 1,8-octanedithiol, as seen from in 1-D out of-plane X-ray profiles normalized by film thicknesses (see Fig. 13 (b). The average interlayer spacing was observed to change significantly in the presence of 1,8-octanedithiol. It was concluded that the interaction between P3HT is stronger in the presence of 1,8-octanedithiol with the P3HT crystallinity improved due to stacking. The size distribution of P3HT crystals was found to be broader with increasing amount of 1,8-octanedithiol, as shown in Fig. 13 (c). 
Improved crystallization of P3HT and broader crystal size distribution at higher 1,8-octanedithiol concentrations was explained by solvent volume ratios. During the film fabrication, the main solvent evaporates faster than the additive solvent resulting in a sudden increase of the volume ratio of the additive solvent to the main solvent. Polymer molecules lower their internal energy by aggregating when the additive solvent volume ratio reaches a critical point. At higher additive concentrations, the time required to reach this point is reduced and aggregation is stronger. As a result, polymer molecules aggregate with larger average domain sizes due to the stronger driving force and broader size distributions arises due to the shorter aggregation time.

\section{Schematic structures of bulk-heterojunction film morphology}

The morphological studies discussed above highlight the importance of phase separation between donor and acceptor, and reveal a schematic film structures for polymer-based bulk-heterojunction solar cells, as shown in Fig. 14..(Hoppe et al., 2006; Huang et al., 2010; Peumans et al., 2003)

In the top Fig. 14 (a), the percolated pathways for electrons and holes is created allowing them to reach the respective electrodes. In Fig. $14 \mathrm{~b}$ the situation for an enclosed PCBM cluster is shown: here electrons and holes will recombine, since percolation is insufficient.

The center Fig. 14 show that the lower surface energy of P3HT, relative to PCBM, provides the driving force for the interconcentration gradient observed in both the rapidly (a) and slowly (b) grown films. The film prepared through a rapidly grown process leads to an extremely homogeneous blends. A greater number of percolating pathways are formed in slow grown films.

Furthermore, the effect of annealing on the interface morphology of a mixed-layer device was modeled using a cellular model, as shown in Fig. 14 (bottom) for different temperatures. Annealing temperatures has been shown to crucially influence the morphology of the mixed-layer device, while the modeled morphology resemble experimentally measured devices.

\section{Processing additive effect on solar cell performance}

The photophysical effects of 1,8-octanedithiol (ODT) additives on PCPDTBT and C71-PCBM composites and device performance were studied using photo-induced absorption spectroscopy.(Hwang et al., 2008) Reduced carrier loss due to recombination was found in BHJ films processed using the additive. From photobleaching recovery measurements reduced carrier losses were demonstrated. However, it was concluded that the amount of the reduction is not sufficient to explain the observed increase in the power conversion efficiency (by a factor of 2). Carrier mobility measurements in Field Effect Transistor (FET) configuration demonstrated that the electron mobility increased in the PCPDTBT:C71-PCBM when ODT is used as an additive, resulting in enhanced connectivity of C71-PCBM networks.(Cho et al., 2008) This work also showed that if the ODT was not completely removed from the BHJ films by placing them in high vacuum ( $>10^{-6}$ torr) the hole mobility actually decreased, implying that residual ODT may act as a hole trap. It was concluded that the improved electron mobility was the primary cause of the improved power conversion efficiency, while the hole mobility was found to be relatively insensitive to the additive. 


\subsection{Power conversion efficiency and current-voltage dependence}

In order to clarify the effect of chemical additives on the photophysical properties and photovoltaic performance, regioregular P3HT and PCBM bulk-heterojunction solar cells were fabricated in four different ways:

(1) as produced films (untreated, no alkyl thiol);

(2) thermally annealed films (refereed to as treated in text, no alkyl thiol);

(3) as produced films with alkyl thiol (refereed to as treated in text, with alkyl thiol);

(4) thermally annealed films with alkyl thiol (refereed to as treated in text, with alkyl thiol).

The fabrication procedures were kept the same for all four types of cells. The details on device preparation can be found elsewhere.(Pivrikas et al., 2008)

Current-voltage (I-V) characteristics under illumination of devices are shown in Fig. 15. Untreated solar cells gave the worst performance with the least short circuit current and low fill factor. However, these cells demonstrate a relatively higher open circuit voltage, but, due to a low short circuit current and a low fill factor, their power conversion efficiency was low, around $1 \%$. The difference in photocurrents between annealed cells and these with alkyl thiol

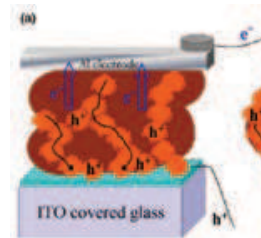

(a)

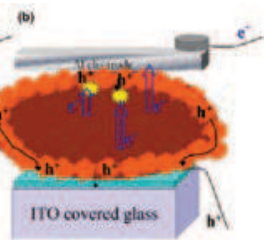

(b)

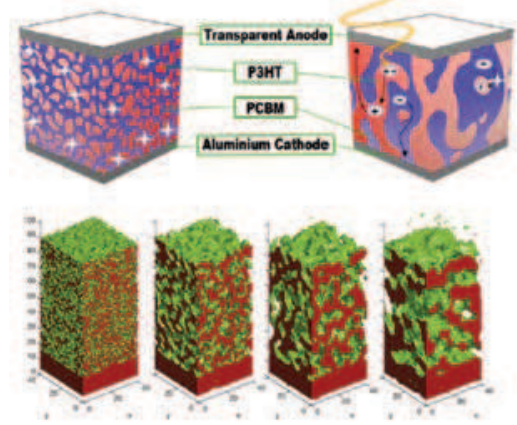

Fig. 14. Schematic structures of the film nanomorphology of bulk-heterojunction blends - all emphasizing the importance of the interpenetrating network in polymer-based solar cells. Top figures: (a) chlorobenzene and (b) toluene cast MDMO-PPV and PCBM blend layers. Center figures: vertical phase morphology of (a) rapidly and (b) slowly grown P3HT and PCBM blends. Bottom figures: the simulated effects of annealing on the interface morphology of a mixed-layer photovoltaic cell. The interface between donor and acceptor is shown as a green surface. Donor is shown in red and acceptor is transparent. Top figures reprinted with permission from (Hoppe et al., 2006), copyright 2006, with permission from Elsevier. Middle figures reprinted with permission from (Huang et al., 2010), copyright 2010 American Chemical Society. Bottom figures adapted by permission from Macmillan Publishers Ltd: (Peumans et al., 2003), copyright 2003. 


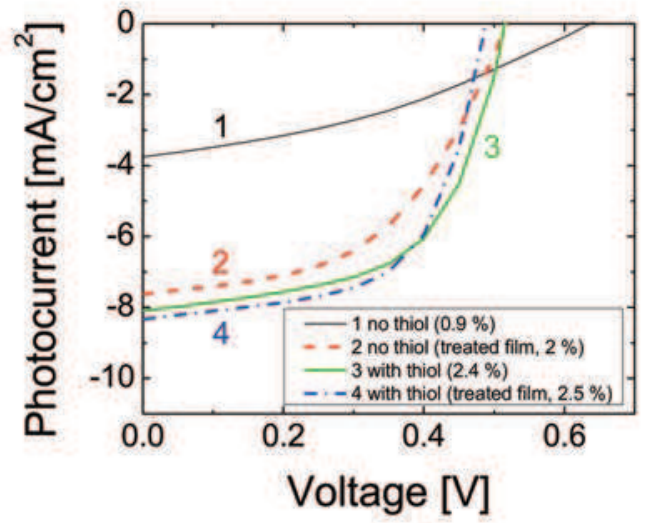

Fig. 15. Current-voltage characteristics demonstrating significant performance improvement under illumination ( $\left.1000 \mathrm{~W} / \mathrm{m}^{2}, 1.5 \mathrm{AM}\right)$ for P3HT/PCBM bulk-heterojunction solar cells prepared in different ways: as produced (thin line), annealed (thick dashed line), thiol added (thick line), thiol added and annealed (thick dash dot line). Reprinted with permission from (Pivrikas et al., 2008). Copyright 2008, with permission from Elsevier.

is small, except that treated cells have lower fill factors and therefore slightly lower efficiency as compared to those with alkyl thiol additive, Fig. 16.

\subsection{Light absorption and external quantum efficiency}

In order to clarify the factors determining OPV device efficiency, the incident photon to current efficiency (IPCE), alternatively called External Quantum Efficiency (EQE) is measured, since it provides information on light absorption spectra, charge transport and recombination losses. The effect of thermal treatment versus processing addictive, as well as the effect of additive concentration, was studied and shown in Fig. 16. In Fig. 16 (a) and (d) the light absorption and Beer-Lambert absorption coefficient are shown as a function of wavelength. In agreement with previous observations, an increase in optical absorption is seen for treated cells. The red-shift of the absorption and characteristic vibronic shoulders are clearly pronounced in treated cells (at around $517 \mathrm{~nm}, 556 \mathrm{~nm}$ and $603 \mathrm{~nm}$ ) both arising from strong interchain interactions within high degree of crystallinity in P3HT. In solution, no peak shift was observed, suggesting that the influence of the additive on P3HT happens during the solvent drying (or spin coating) process and not in the solution state. The increase in optical absorption at higher additive concentrations demonstrates that more energy can be harvested in solar cells, therefore, these cells have better photovoltaic performance due to a larger amount of photons being absorbed in the film.

While PCBM is known to quench the PL of P3HT effectively in the well mixed blends.(Chen, Yang, Yang, Sista, Zadoyan, Li \& Yang, 2009) The photoluminescence was shown to increase with increasing amount of 1,8-octanedithiol (Fig. 16 (b)), suggesting that the phase separation between the P3HT and PCBM is increasing since the exciton diffusion distance is on the same order of magnitude.(Xu \& Holdcroft, 1993; Zhokhavets et al., 2006) 

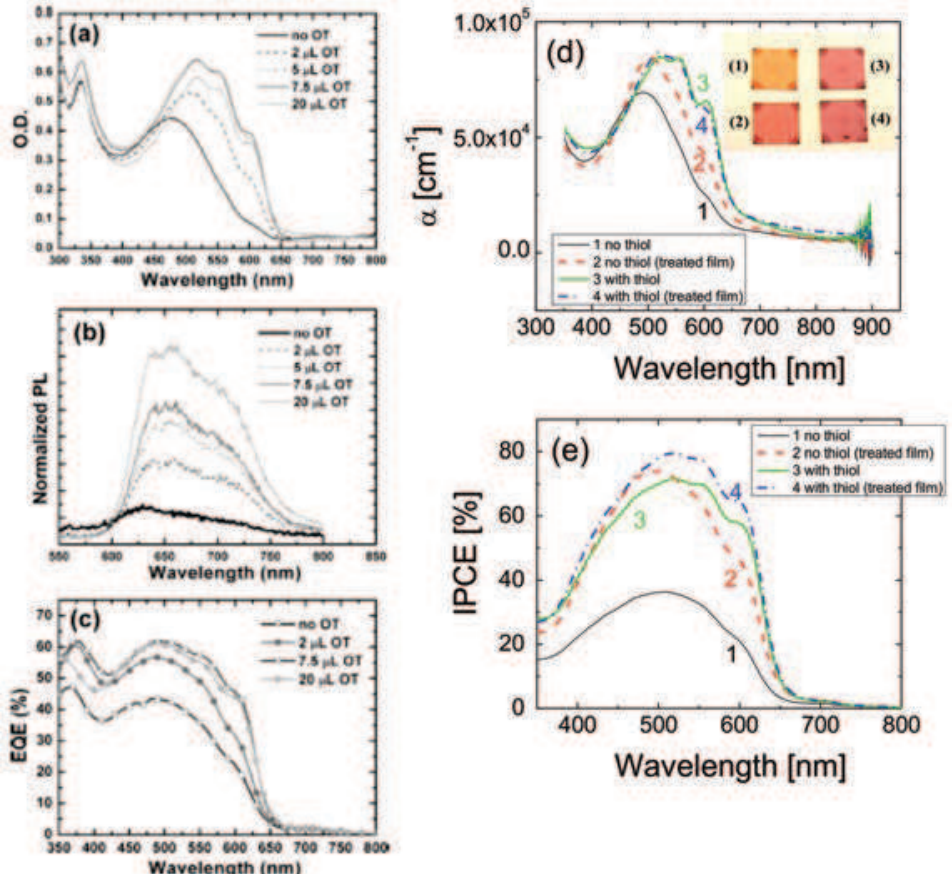

Fig. 16. Changes in light absorption (a) and photoluminescence (PL) (b) and External Quantum Efficiency (EQE) (c) shown at various amounts of processing additive (OT is 1,8-octanedithiol) used during film preparation. Changes in light absorption (d) and incident photon to current efficiency (IPCE) in (e) measured in pristine and treated (annealed films and films fabricated with processing additive) films. Strong red-shift in absorption, appearance of absorption peaks, higher IPCE values in treated films or films with processing additive well agrees with improved OPV performance. Thermal annealing of films fabricated with processing additive results in no change in OPV performance. Figures on the left reprinted with permission from (Chen, Yang, Yang, Sista, Zadoyan, Li \& Yang, 2009). Copyright 2009 American Chemical Society. Figures on the right reprinted with permission from (Pivrikas et al., 2008). Copyright 2008, with permission from Elsevier.

A strong improvement in IPCE was observed in treated solar cells. The IPCE dependence approximately follows the light absorption curve, as the same characteristic absorption peaks are reproduced in the optical absorption spectra (Fig. 16). From the IPCE studies it was concluded that the improvement in the performance of solar cells is not only due to the increased optical absorption, but also due to improved transport (higher carrier mobility) and/or reduced recombination losses (eg. due to longer charge carrier lifetime), which again confirms the benefits of improved interpenetrating network between donor and acceptor.

\subsection{Charge transport}

Since it was found from ICPE studies that the film morphology not only improves the light absorption, but also results in better charge transport, it is important to quantify this improvement. In order to understand the difference in charge transport properties in treated 
and untreated cells, dark IV curves were recorded for all 4 types of treated cells shown in Fig. 17.(Pivrikas et al., 2008)
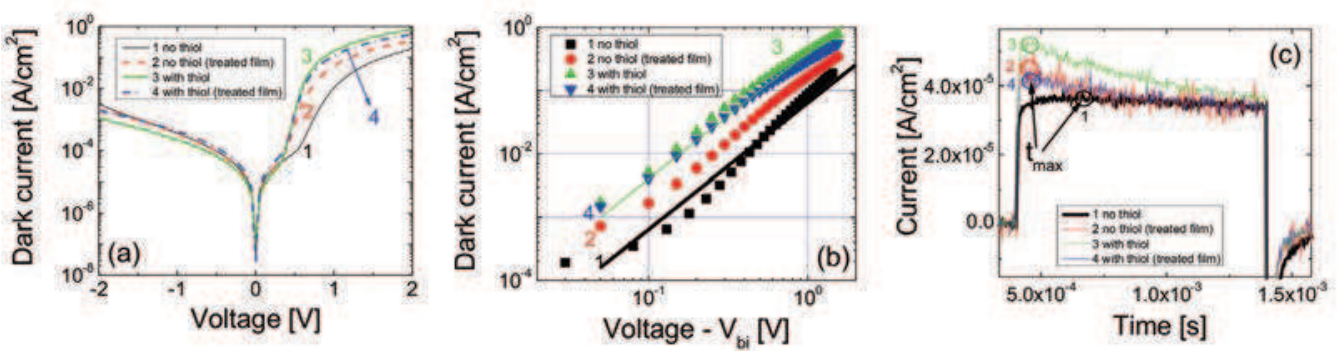

Fig. 17. The improvement in charge carrier mobility in treated (annealed films and films fabricated with processing additive) compared to pristine films demonstrated by two methods: dark current-voltage injection and CELIV. (a) log-lin plot showing the rectification ratio in forward and reverse bias and insignificant differences in leakage current in reverse bias. (b) log-log plot in forward bias showing much higher injection current levels in treated blends. (c) faster carrier extraction in treated films compared to pristine directly measured by CELIV current transients. Improvement in the carrier mobility can be seen from the shift in the position of extraction maximum, while experimental conditions (film thicknesses and applied voltages ) were kept similar. Thermal annealing of films fabricated with processing additive results in no change in performance. Reprinted with permission from (Pivrikas et al., 2008). Copyright 2008, with permission from Elsevier.

The dark current in the region of negative applied voltage (the reverse bias, positive voltage on $\mathrm{Al}$, negative on ITO), is similar in all cells, showing that current injection is contact limited. A significant rectification ratio is observed for all types of studied cells. The dark leakage current in reverse bias is rather high, but similar for all cells.

Due to the different nanomorphologies of the interpenetrating network, the dark conductivity is expected to increase in the cells with higher conversion efficiency, because of improved conductivity of the films (assuming the injection is not limited by the contact). The dark injection current in forward bias is observed to be significantly higher in treated cells. In Fig. 17 (b) the dark injection current in forward bias is plotted in log-log scale for all devices. Faster charge carrier mobilities in all cells were estimated from these dependences using the Mott-Gurney Law. As can be directly seen from the magnitude of injection current, the highest mobility was observed in the films with chemical additives, confirming the beneficial effect of chemical additives for charge transport in bulk-heterojunction solar cells. From CELIV measurements, shown in Fig. 17 (c) it was demonstrated that charge carrier mobility is mainly reponsible for improvements in OPV performance.

However, the charge carrier recombination processes in operating devices has yet to be clarified. It was shown that the typically expected Langevin bimolecular charge carrier recombination can be avoided in highly efficiency P3HT and PCBM blends.(Pivrikas et al., 2005) Non-Langevin carrier recombination was shown to be crucially important in low mobility organic photovoltaic devices, since the requirement for the slower carrier mobility can be reduced without recombination losses. This implies that close to unity Internal quantum efficiency can be reached in low bandgap organic materials with very low carrier mobility if reduced bimolecular recombination (non-Langevin) is present in the device. 


\section{Conclusions}

The film nanomorphology of bulk heterojunction solar cells determines the power conversion efficiency through photophysical properties such as light absorption, exciton dissociation, charge transport and recombination. The nano-morphology can be controlled by a variety of different methods. Thermal annealing of fabricated solar cells can be successfully substituted with slow drying of the solvent or chemical additives. These methods induce the phase separation between the donor and acceptor in the bulk-heterojunction, which results in red-shifted light absorption, improved exciton dissociation, faster charge carrier transport, and reduced recombination. Segregated donor-enriched and/or acceptor-enriched phases can be formed resulting in an interpenetrating bicontinuous network with the domain sizes comparable to the exciton diffusion length. Interconnected pathways for electromn and hole transport to the electrodes are required. This structure is essential for the photovoltaic performance of polymer-based solar cells. Therefore, reproducible, low cost nano-structure control is crucially important for fabrication of high efficiency OPV suitable for commercialization. In order to be able to control and predict the film nano-morphology of novel materials, an understanding of the material parameters governing the phase separation is required.

\section{Acknowledgements}

The author would like to Dr. Paul Schwenn for helpful discussions during manuscript preparation.

\section{References}

Alargova, R., Deguchi, S. \& Tsujii, K. (2001). Stable colloidal dispersions of fullerenes in polar organic solvents, Journal of the American Chemical Society 123(43): 10460-10467.

Baranovski, S. (2006). Charge transport in disordered solids with applications in electronics, John Wiley \& Sons Inc.

Bassler, H. (1993). Charge transport in disordered organic photoconductors a monte carlo simulation study, physica status solidi (b) 175(1): 15-56.

Bechara, R., Leclerc, N., Lévêque, P., Richard, F., Heiser, T. \& Hadziioannou, G. (2008). Efficiency enhancement of polymer photovoltaic devices using thieno-thiophene based copolymers as nucleating agents for polythiophene crystallization, Applied Physics Letters 93: 013306.

Brabec, C. (2004). Organic photovoltaics: technology and market, Solar energy materials and solar cells 83(2-3): 273-292.

Brabec, C., Sariciftci, N., Hummelen, J. et al. (2001). Plastic solar cells, Advanced Functional Materials 11(1): 15-26.

Campbell, A., Hodgkiss, J., Westenhoff, S., Howard, I., Marsh, R., McNeill, C., Friend, R. \& Greenham, N. (2008). Low-temperature control of nanoscale morphology for high performance polymer photovoltaics, Nano letters 8(11): 3942-3947.

Chen, F., Tseng, H. \& Ko, C. (2008). Solvent mixtures for improving device efficiency of polymer photovoltaic devices, Applied Physics Letters 92: 103316.

Chen, F., Xu, Q. \& Yang, Y. (2004). Enhanced efficiency of plastic photovoltaic devices by blending with ionic solid electrolytes, Applied physics letters 84: 3181. 
Chen, H., Yang, H., Yang, G., Sista, S., Zadoyan, R., Li, G. \& Yang, Y. (2009). Fast-grown interpenetrating network in poly (3-hexylthiophene): Methanofullerenes solar cells processed with additive, The Journal of Physical Chemistry C 113(18): 7946-7953.

Chen, L., Hong, Z., Li, G. \& Yang, Y. (2009). Recent progress in polymer solar cells: manipulation of polymer: fullerene morphology and the formation of efficient inverted polymer solar cells, Advanced Materials 21(14-15): 1434-1449.

Cho, S., Lee, J., Moon, J., Yuen, J., Lee, K. \& Heeger, A. (2008). Bulk heterojunction bipolar field-effect transistors processed with alkane dithiol, Organic Electronics 9(6): 1107-1111.

Chu, C., Yang, H., Hou, W., Huang, J., Li, G. \& Yang, Y. (2008). Control of the nanoscale crystallinity and phase separation in polymer solar cells, Applied Physics Letters 92: 103306.

Coates, N., Hwang, I., Peet, J., Bazan, G., Moses, D. \& Heeger, A. (2008). 1, 8-octanedithiol as a processing additive for bulk heterojunction materials: Enhanced photoconductive response, Applied Physics Letters 93: 072105.

Cohen, E. \& Gutoff, E. (1992). Modern coating and drying technology, VCH.

Cox, P., Betts, R., Jones, C., Spall, S. \& Totterdell, I. (2000). Acceleration of global warming due to carbon-cycle feedbacks in a coupled climate model, Nature 408(6809): 184-187.

Deibel, C. \& Dyakonov, V. (2010). Polymer-fullerene bulk heterojunction solar cells, Reports on Progress in Physics 73: 096401.

Dennler, G., Scharber, M. \& Brabec, C. (2009). Polymer-fullerene bulk-heterojunction solar cells, Advanced Materials 21(13): 1323-1338.

Erb, T., Zhokhavets, U., Gobsch, G., Raleva, S., ST

"uHN, B., Schilinsky, P., Waldauf, C. \& Brabec, C. (2005). Correlation between structural and optical properties of composite polymer/fullerene films for organic solar cells, Advanced Functional Materials 15(7): 1193-1196.

Forrest, S. (2005a). The limits to organic photovoltaic cell efficiency, MRS bulletin 30(01): 28-32.

Forrest, S. (2005b). The path to ubiquitous and low-cost organic electronic appliances on plastic, Gravitational, electric, and magnetic forces: an anthology of current thought p. 120.

Glaser, P. (1968). Power from the sun: Its future, Science 162(3856): 857.

Gunes, S., Neugebauer, H. \& Sariciftci, N. (2007). Conjugated polymer-based organic solar cells, Chemical reviews 107(4): 1324-1338.

Halls, J., Walsh, C., Greenham, N., Marseglia, E., Friend, R., Moratti, S. \& Holmes, A. (1995). Efficient photodiodes from interpenetrating polymer networks.

Hecht, K. (1932). Zum mechanismus des lichtelektrischen primärstromes in isoliereden kristallen, Z. Phys 77: 235.

Hoppe, H., Glatzel, T., Niggemann, M., Schwinger, W., Schaeffler, F., Hinsch, A., Lux-Steiner, M. \& Sariciftci, N. (2006). Efficiency limiting morphological factors of mdmo-ppv: Pcbm plastic solar cells, Thin solid films 511: 587-592.

Hoppea, H. \& Sariciftci, N. (2004). Organic solar cells: An overview, J. Mater. Res 19(7): 1925.

Huang, J., Chien, F., Chen, P., Ho, K. \& Chu, C. (2010). Monitoring the 3d nanostructures of bulk heterojunction polymer solar cells using confocal lifetime imaging, Analytical chemistry 82(5): 1669-1673.

Hwang, I., Cho, S., Kim, J., Lee, K., Coates, N., Moses, D. \& Heeger, A. (2008). Carrier generation and transport in bulk heterojunction films processed with 1, 8-octanedithiol as a processing additive, Journal of Applied Physics 104(3): 033706-033706. 
Ihn, K., Moulton, J. \& Smith, P. (1993). Whiskers of poly (3-alkylthiophene) s, Journal of Polymer Science Part B: Polymer Physics 31(6): 735-742.

Jorgensen, M., Norrman, K. \& Krebs, F. (2008). Stability/degradation of polymer solar cells, Solar Energy Materials and Solar Cells 92(7): 686-714.

Juska, G., Genevičius, K.,

"Osterbacka, R., Arlauskas, K., Kreouzis, T., Bradley, D. \& Stubb, H. (2003). Initial transport of photogenerated charge carriers in $\pi$-conjugated polymers, Physical Review B 67(8): 081201.

Kim, K., Liu, J. \& Carroll, D. (2006). Thermal diffusion processes in bulk heterojunction formation for poly-3-hexylthiophene/c60 single heterojunction photovoltaics, Applied physics letters 88(18): 181911-181911.

Kim, Y., Choulis, S., Nelson, J., Bradley, D., Cook, S. \& Durrant, J. (2005). Device annealing effect in organic solar cells with blends of regioregular poly (3-hexylthiophene) and soluble fullerene, Applied Physics Letters 86(6): 063502-063502.

Kim, Y., Cook, S., Choulis, S., Nelson, J., Durrant, J. \& Bradley, D. (2005). Effect of electron-transport polymer addition to polymer/fullerene blend solar cells, Synthetic metals 152(1-3): 105-108.

Kim, Y., Cook, S., Tuladhar, S., Choulis, S., Nelson, J., Durrant, J., Bradley, D., Giles, M., McCulloch, I., Ha, C. et al. (2006). A strong regioregularity effect in self-organizing conjugated polymer films and high-efficiency polythiophene: fullerene solar cells, nature materials 5(3): 197-203.

Krebs, F. (2009). Fabrication and processing of polymer solar cells: a review of printing and coating techniques, Solar Energy Materials and Solar Cells 93(4): 394-412.

Lee, J., Ma, W., Brabec, C., Yuen, J., Moon, J., Kim, J., Lee, K., Bazan, G. \& Heeger, A. (2008). Processing additives for improved efficiency from bulk heterojunction solar cells, Journal of the American Chemical Society 130(11): 3619-3623.

Li, G., Shrotriya, V., Huang, J., Yao, Y., Moriarty, T., Emery, K. \& Yang, Y. (2005). High-efficiency solution processable polymer photovoltaic cells by self-organization of polymer blends, Nature Materials 4(11): 864-868.

Li, G., Shrotriya, V., Yao, Y., Huang, J. \& Yang, Y. (2007). Manipulating regioregular poly (3-hexylthiophene):[6, 6]-phenyl-c61-butyric acid methyl ester blends-route towards high efficiency polymer solar cells, Journal of Materials Chemistry 17(30): 3126-3140.

Li, G., Yao, Y., Yang, H., Shrotriya, V., Yang, G. \& Yang, Y. (2007). Şsolvent annealingŤ effect in polymer solar cells based on poly (3-hexylthiophene) and methanofullerenes, Advanced Functional Materials 17(10): 1636-1644.

Li, L., Lu, G. \& Yang, X. (2008). Improving performance of polymer photovoltaic devices using an annealing-free approach via construction of ordered aggregates in solution, J. Mater. Chem. 18(17): 1984-1990.

Luque, A. \& Hegedus, S. (2003). Handbook of photovoltaic science and engineering, John Wiley \& Sons Inc.

Ma, W., Yang, C., Gong, X., Lee, K. \& Heeger, A. (2005). Thermally stable, efficient polymer solar cells with nanoscale control of the interpenetrating network morphology, Advanced Functional Materials 15(10): 1617-1622.

Mayer, A., Toney, M., Scully, S., Rivnay, J., Brabec, C., Scharber, M., Koppe, M., Heeney, M., McCulloch, I. \& McGehee, M. (2009). Bimolecular crystals of fullerenes in conjugated polymers and the implications of molecular mixing for solar cells, Adv. Funct. Mater 19(8): 1173-1179. 
Mihailetchi, V., Xie, H., de Boer, B., Popescu, L., Hummelen, J., Blom, P. \& Koster, L. (2006). Origin of the enhanced performance in poly (3-hexylthiophene):[6, 6]-phenyl c-butyric acid methyl ester solar cells upon slow drying of the active layer, Applied physics letters 89: 012107.

Moule, A. \& Meerholz, K. (2008). Controlling morphology in polymer-fullerene mixtures, Advanced Materials 20(2): 240-245.

Moulee, A., Tsami, A., B "unnagel, T., Forster, M., Kronenberg, N., Scharber, M., Koppe, M., Morana, M., Brabec, C., Meerholz, K. et al. (2008). Two novel cyclopentadithiophene-based alternating copolymers as potential donor components for high-efficiency bulk-heterojunction-type solar cells, Chemistry of Materials 20(12): 4045-4050.

Nayak, P., Bisquert, J. \& Cahen, D. (2011). Assessing possibilities and limits for solar cells, Advanced Materials .

Nelson, J. (2003). The physics of solar cells, Imperial College Press London.

Norrman, K., Ghanbari-Siahkali, A. \& Larsen, N. (2005). 6 studies of spin-coated polymer films, Annu. Rep. Prog. Chem., Sect. C: Phys. Chem. 101: 174-201.

Oesterbacka, R., Pivrikas, A., Juska, G., Poskus, A., Aarnio, H., Sliauzys, G., Genevicius, K., Arlauskas, K. \& Sariciftci, N. (2010). Effect of 2-d delocalization on charge transport and recombination in bulk-heterojunction solar cells, IEEE Journal of Selected Topics in Quantum Electronics 16(6): 1738-1745.

Osterbacka, R., Geneviius, K., Pivrikas, A., Juka, G., Arlauskas, K., Kreouzis, T., Bradley, D. \& Stubb, H. (2003). Quantum efficiency and initial transport of photogenerated charge carriers in [pi]-conjugated polymers, Synthetic metals 139(3): 811-813.

Ouyang, J. \& Xia, Y. (2009). High-performance polymer photovoltaic cells with thick p3ht: Pcbm films prepared by a quick drying process, Solar Energy Materials and Solar Cells 93(9): 1592-1597.

Padinger, F., Rittberger, R. \& Sariciftci, N. (2003). Effects of postproduction treatment on plastic solar cells, Advanced Functional Materials 13(1): 85-88.

Peet, J., Brocker, E., Xu, Y. \& Bazan, G. (2008). Controlled $\beta$-phase formation in poly (9, 9-di-n-octylfluorene) by processing with alkyl additives, Advanced Materials 20(10): 1882-1885.

Peet, J., Kim, J., Coates, N., Ma, W., Moses, D., Heeger, A. \& Bazan, G. (2007). Efficiency enhancement in low-bandgap polymer solar cells by processing with alkane dithiols, Nature Materials 6(7): 497-500.

Peet, J., Senatore, M., Heeger, A. \& Bazan, G. (2009). The role of processing in the fabrication and optimization of plastic solar cells, Advanced Materials 21(14-15): 1521-1527.

Peet, J., Soci, C., Coffin, R., Nguyen, T., Mikhailovsky, A., Moses, D. \& Bazan, G. (2006). Method for increasing the photoconductive response in conjugated polymer/fullerene composites, Applied physics letters 89(25): 252105-252105.

Peumans, P., Uchida, S. \& Forrest, S. (2003). Efficient bulk heterojunction photovoltaic cells using small-molecular-weight organic thin films, Nature 425(6954): 158-162.

Pivrikas, A., Juška, G., Mozer, A., Scharber, M., Arlauskas, K., Sariciftci, N., Stubb, H. \& "Osterbacka, R. (2005). Bimolecular recombination coefficient as a sensitive testing parameter for low-mobility solar-cell materials, Physical review letters 94(17): 176806.

Pivrikas, A., Neugebauer, H. \& Sariciftci, N. (2010a). Charge carrier lifetime and recombination in bulk heterojunction solar cells, Selected Topics in Quantum Electronics, IEEE Journal of 16(6): 1746-1758. 
Pivrikas, A., Neugebauer, H. \& Sariciftci, N. (2010b). Influence of processing additives to nano-morphology and efficiency of bulk-heterojunction solar cells: A comparative review, Solar Energy .

Pivrikas, A., Stadler, P., Neugebauer, H. \& Sariciftci, N. (2008). Substituting the postproduction treatment for bulk-heterojunction solar cells using chemical additives, Organic Electronics 9(5): 775-782.

PIVRIKAS, A., ULLAH, M., SINGH, T., SIMBRUNNER, C., MATT, G., SITTER, H. \& SARICIFTCI, N. (2011). Meyer-neldel rule for charge carrier transport in fullerene devices: A comparative study, Organic electronics 12(1): 161-168.

Pivrikas, A., Ullah, M., Sitter, H. \& Sariciftci, N. (2011). Electric field dependent activation energy of electron transport in fullerene diodes and field effect transistors: GillŠs law, Applied Physics Letters 98: 092114.

Rughooputh, S., Hotta, S., Heeger, A. \& Wudl, F. (1987). Chromism of soluble polythienylenes, Journal of Polymer Science Part B: Polymer Physics 25(5): 1071-1078.

Sariciftci, N. (2006). Morphology of polymer/fullerene bulk heterojunction solar cells, Journal of Materials Chemistry 16(1): 45-61.

Scharber, M., M "uhlbacher, D., Koppe, M., Denk, P., Waldauf, C., Heeger, A. \& Brabec, C. (2006). Design rules for donors in bulk-heterojunction solar cellsŮtowards $10 \%$ energy-conversion efficiency, Advanced Materials 18(6): 789-794.

Schwoerer, M. \& Wolf, H. (2007). Organic molecular solids, Wiley Online Library.

Shaheen, S., Brabec, C., Sariciftci, N., Padinger, F., Fromherz, T. \& Hummelen, J. (2001). 2.5\% efficient organic plastic solar cells, Applied Physics Letters 78: 841.

Shockley, W. \& Queisser, H. (1961). Detailed balance limit of efficiency of p-n junction solar cells, Journal of Applied Physics 32(3): 510-519.

Shrotriya, V., Li, G., Yao, Y., Moriarty, T., Emery, K. \& Yang, Y. (2006). Accurate measurement and characterization of organic solar cells, Advanced Functional Materials 16(15): 2016-2023.

Sivula, K., Ball, Z., Watanabe, N. \& Fréchet, J. (2006). Amphiphilic diblock copolymer compatibilizers and their effect on the morphology and performance of polythiophene: fullerene solar cells, Advanced Materials 18(2): 206-210.

Sun, S., Zhang, C., Ledbetter, A., Choi, S., Seo, K., Bonner, C., Drees, M. \& Sariciftci, N. (2007). Photovoltaic enhancement of organic solar cells by a bridged donor-acceptor block copolymer approach, Applied physics letters 90(4): 043117-043117.

Treat, N., Brady, M., Smith, G., Toney, M., Kramer, E., Hawker, C. \& Chabinyc, M. (2011). Interdiffusion of pcbm and p3ht reveals miscibility in a photovoltaically active blend, Laser Physics Review 1: 82-89.

Troshin, P., Hoppe, H., Renz, J., Egginger, M., Mayorova, J., Goryachev, A., Peregudov, A., Lyubovskaya, R., Gobsch, G., Sariciftci, N. et al. (2009). Material solubility-photovoltaic performance relationship in the design of novel fullerene derivatives for bulk heterojunction solar cells, Adv. Funct. Mater 19: 779-788.

Turner, J. (1999). A realizable renewable energy future, Science 285(5428): 687.

van Duren, J., Yang, X., Loos, J., Bulle-Lieuwma, C., Sieval, A., Hummelen, J. \& Janssen, R. (2004). Relating the morphology of poly (p-phenylene vinylene)/methanofullerene blends to solar-cell performance, Advanced Functional Materials 14(5): 425-434. 
Vanlaeke, P., Vanhoyland, G., Aernouts, T., Cheyns, D., Deibel, C., Manca, J., Heremans, P. \& Poortmans, J. (2006). Polythiophene based bulk heterojunction solar cells: Morphology and its implications, Thin Solid Films 511: 358-361.

Wienk, M., Turbiez, M., Gilot, J. \& Janssen, R. (2008). Narrow-bandgap diketo-pyrrolo-pyrrole polymer solar cells: The effect of processing on the performance, Advanced Materials 20(13): 2556-2560.

Wohrle, D. \& Meissner, D. (1991). Organic solar cells, Advanced Materials 3(3): 129-138.

Xin, H., Kim, F. \& Jenekhe, S. (2008). Highly efficient solar cells based on poly (3-butylthiophene) nanowires, Journal of the American Chemical Society 130(16): 5424-5425.

$\mathrm{Xu}$, B. \& Holdcroft, S. (1993). Molecular control of luminescence from poly (3-hexylthiophenes), Macromolecules 26(17): 4457-4460.

Yang, C., Qiao, J., Sun, Q., Jiang, K., Li, Y. \& Li, Y. (2003). Improvement of the performance of polymer/c60 photovoltaic cells by small-molecule doping, Synthetic metals 137(1-3): 1521-1522.

Yang, X., Loos, J., Veenstra, S., Verhees, W., Wienk, M., Kroon, J., Michels, M. \& Janssen, R. (2005). Nanoscale morphology of high-performance polymer solar cells, Nano Letters 5(4): 579-583.

Yao, Y., Hou, J., Xu, Z., Li, G. \& Yang, Y. (2008). Effects of solvent mixtures on the nanoscale phase separation in polymer solar cells, Advanced Functional Materials 18(12): 1783-1789.

Yao, Y., Shi, C., Li, G., Shrotriya, V., Pei, Q. \& Yang, Y. (2006). Effects of c70 derivative in low band gap polymer photovoltaic devices: Spectral complementation and morphology optimization, Applied physics letters 89(15): 153507-153507.

Yu, G., Gao, J., Hummelen, J., Wudl, F. \& Heeger, A. (1995). Polymer photovoltaic cells: enhanced efficiencies via a network of internal donor-acceptor heterojunctions, Science 270(5243): 1789.

Zhang, C., Choi, S., Haliburton, J., Cleveland, T., Li, R., Sun, S., Ledbetter, A. \& Bonner, C. (2006). Design, synthesis, and characterization of a-donor-bridge-acceptor-bridge-type block copolymer via alkoxy-and sulfone-derivatized poly (phenylenevinylenes), Macromolecules 39(13): 4317-4326.

Zhang, F., Jespersen, K., Björström, C., Svensson, M., Andersson, M., Sundstr"om, V., Magnusson, K., Moons, E., Yartsev, A. \& Ingan"as, O. (2006). Influence of solvent mixing on the morphology and performance of solar cells based on polyfluorene copolymer/fullerene blends, Advanced Functional Materials 16(5): 667-674.

Zhokhavets, U., Erb, T., Hoppe, H., Gobsch, G. \& Serdar Sariciftci, N. (2006). Effect of annealing of poly (3-hexylthiophene)/fullerene bulk heterojunction composites on structural and optical properties, Thin Solid Films 496(2): 679-682. 


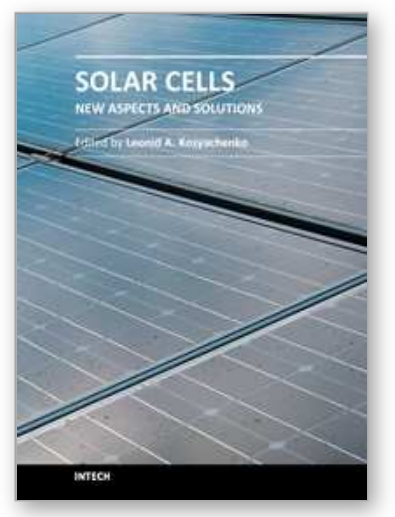

\author{
Solar Cells - New Aspects and Solutions \\ Edited by Prof. Leonid A. Kosyachenko
}

ISBN 978-953-307-761-1

Hard cover, 512 pages

Publisher InTech

Published online 02, November, 2011

Published in print edition November, 2011

The fourth book of the four-volume edition of 'Solar cells' consists chapters that are general in nature and not related specifically to the so-called photovoltaic generations, novel scientific ideas and technical solutions, which has not properly approved. General issues of the efficiency of solar cell and through hydrogen production in photoelectrochemical solar cell are discussed. Considerable attention is paid to the quantum-size effects in solar cells both in general and on specific examples of super-lattices, quantum dots, etc. New materials, such as cuprous oxide as an active material for solar cells, AlSb for use as an absorber layer in $p$-i-n junction solar cells, InGaAsN as a promising material for multi-junction tandem solar cells, InP in solar cells with MIS structures are discussed. Several chapters are devoted to the analysis of both status and perspective of organic photovoltaics such as polymer/fullerene solar cells, poly( $p$-phenylene-vinylene) derivatives, photovoltaic textiles, photovoltaic fibers, etc.

\title{
How to reference
}

In order to correctly reference this scholarly work, feel free to copy and paste the following:

Almantas Pivrikas (2011). Relation Between Nanomorphology and Performance of Polymer-Based Solar Cells, Solar Cells - New Aspects and Solutions, Prof. Leonid A. Kosyachenko (Ed.), ISBN: 978-953-307-761-1, InTech, Available from: http://www.intechopen.com/books/solar-cells-new-aspects-and-solutions/relationbetween-nanomorphology-and-performance-of-polymer-based-solar-cells

\section{INTECH}

open science | open minds

\section{InTech Europe}

University Campus STeP Ri

Slavka Krautzeka 83/A

51000 Rijeka, Croatia

Phone: +385 (51) 770447

Fax: +385 (51) 686166

www.intechopen.com

\section{InTech China}

Unit 405, Office Block, Hotel Equatorial Shanghai

No.65, Yan An Road (West), Shanghai, 200040, China

中国上海市延安西路65号上海国际贵都大饭店办公楼 405 单元

Phone: +86-21-62489820

Fax: $+86-21-62489821$ 
(C) 2011 The Author(s). Licensee IntechOpen. This is an open access article distributed under the terms of the Creative Commons Attribution 3.0 License, which permits unrestricted use, distribution, and reproduction in any medium, provided the original work is properly cited. 